\title{
Self-Efficacy and Positive Life Orientation in Prostitutes
}

\author{
Dr. Soni Kewalramani ${ }^{1 *}$, Ms. Shreya Srivastava ${ }^{2}$
}

\section{ABSTRACT}

Prostitution is the business or practice of engaging in sexual relations in exchange for payment or some other benefit. Though very common in society, this is one segment of population which is not studied psychologically in depth. Very few researches are reported in literature which studies them from the perspective of positive psychology. The present study is one such attempt. The objective of the present study is to measure Self-Efficacy and Positive Life Orientation in prostitutes and general population female. The sample of the present study comprised of 50 general population female and 50 prostitutes. Before formulating the assumption, a pilot study was done which led to the understanding that prostitutes do feel a sense of accomplishment. The result of the study, however, do not support the assumption formed that prostitutes will be higher on self-efficacy and positive life orientation. . The present study result shows that Self-Efficacy is higher in general population female than prostitutes and no such difference in Positive Life Orientation in both the population.

Keywords: Prostitution, Self-Efficacy, Positive Life Orientation

Who is a prostitute? Prostitute is a person typically a women who engages in sexual activities in exchange for payment.

Prostitution is the business or practice of engaging in sexual relations in exchange for payment or some other benefit. A person who works in this field is called a prostitute, and is a kind of sex worker. Prostitution is one of the branches of the sex industry. It is a very old and universal phenomenon, and even oftentimes referred to as "the world's oldest profession." Despite its universality, the legal status of prostitution varies from country to country, from being permissible but unregulated, to a punishable crime, or to a regulated profession.

"Prostitute" is derived from the Latin prostituta. Some sources cite the verb as a composition of "pro" meaning "up front" or "forward" and "situere", defined as "to offer up for sale". Another

\footnotetext{
${ }^{1}$ Assistant Professor, Amity University Uttar Pradesh, Lucknow Campus, India

${ }^{2}$ MA Counselling Psychology, Amity University Uttar Pradesh, Lucknow Campus, India

*Responding Author
}

Received: February 28, 2017; Revision Received: March 29, 2017; Accepted: March 30, 2017

(C) 2017 Kewalramani S, Srivastava S; licensee IJIP. This is an Open Access Research distributed under the terms of the Creative Commons Attribution License (www.creativecommons.org/licenses/by/2.0), which permits unrestricted use, distribution, and reproduction in any Medium, provided the original work is properly cited. 


\section{Self-Efficacy and Positive Life Orientation in Prostitutes}

explanation is that "prostituta" is a composition of pro and statuere (to cause to stand, to station, place erect). A literal translation therefore is: "to put up front for sale" or "to place forward". The online Etymology Dictionary states, "The notion of 'sex for hire' is not inherent in the etymology, which rather suggests one 'exposed to lust' or sex 'indiscriminately offered."'

The person who renders sexual services and receives the payment is called a prostitute or sex worker. The word "prostitute" was then carried down through various languages to the presentday Western society. Most sex worker activists groups reject the word "prostitute" and since the late 1970s have used the term "sex worker" instead. However, a "sex worker" can also mean anyone who works within the sex industry or whose work is of a sexual nature and is not limited solely to prostitutes. They vary from either engaging in heterosexual or homosexual activity, and their kind of prostitution occurs in a variety of forms.

\section{Sex Worker}

The term "sex worker" was coined in 1978 by sex worker activist Carol Leigh. Its use became popularized after publication of the anthology, Sex Work: Writings By Women In The Sex Industry in 1987, edited by Frédérique Delacoste and Priscilla Alexander.The term "sex worker" has since spread into much wider use, including in academic publications, by NGOs and labor unions, and by governmental and intergovernmental agencies, such as the World Health Organization.

The term is strongly opposed, however, by many who are morally opposed to the sex industry, such as social conservatives, anti-prostitution feminists, and other prohibitionists. Such groups view prostitution variously as a crime or as victimization, and see the term "sex work" as legitimizing criminal activity or exploitation as a type of labor. A sex worker is a person who works in the sex industry. The term is used in reference to all those in all areas of the sex industry including those who provide direct sexual services as well as the staff of such industries. Some sex workers are paid to engage in sexually explicit behavior which involves varying degrees of physical contact with clients (prostitutes, escorts, some but not all professional dominants); pornography models and actors engage in sexually explicit behavior which are filmed or photographed. Phone sex operators have sexually-oriented conversations with clients, and do auditive sexual roleplay. Other sex workers are paid to engage in live sexual performance, such as web cam sex and performers in live sex shows. Some sex workers perform erotic dances and other acts for an audience (striptease, Go-Go dancing, lap dancing, Neoburlesque, and peep shows).

\section{Factors Driving Entrance into Sex Worker}

Factors causing girls and young women to join sex work revealed common trends push factors included: familial poverty (leading to dropping out of school due to lack of support from parents), education and inherited sex work. Pull factors included: friends, financial need etc. 


\section{Self-Efficacy and Positive Life Orientation in Prostitutes}

these are the push and pull factors that cause girls or young women get indulge into sex work. Money is one of the important factor as one needs money to live. Girls from rural areas have to face many financial problems due to which they had to drop out from school. Low education takes place and due to pressure of parents they indulge in sex work. As they get paid for this job the money is been given to their parents. They are not supposed to be in touch with their family once they entered this field. Mental health also suffers of an individual working in this field so as physical health. There is a strong relationship between mental ill-health, risk-taking behaviors, drug use and sexual behaviours among commercial sex workers. Prostitution is associated with a host of psychosocial vulnerabilities, including exposure to childhood physical abuse, childhood sexual abuse, and interpersonal violence in adulthood and substance uses. As described by Medrano and Gilchrist, prostitution is often linked with socio-demographic disadvantages like minority ethnic status, low income, homelessness and low

\section{Types of Sex Work}

\section{Sex workers as victims of trafficking}

Sex trafficking involves some form of forced or coerced sexual exploitation that is not limited to prostitution, and has become a significant and growing problem in larger global community. Sex trafficking is a critical health issue with broader social implications that requires both medical and legal attention. Healthcare professionals can work to improve the screening, identification, and assistance of victims of sex trafficking in a clinical setting and help these women and girls access legal and social services.

Human trafficking is a modern-day form of slavery that involves the illegal trade of human beings for the purpose of some form of forced exploitation. The United Nations Office On Drugs and Crime (UNODC) defines human trafficking as any form of recruiting, transporting, transferring, harboring, or receiving a person by means of threat or use of force or other forms of coercion, abduction, fraud, or deception.1 There are approximately 800,000 people trafficked across international borders annually and, of these, $80 \%$ are women or girls and 50\% are minors. 2 Although the degree of trafficking among countries and continents is variable, it is clear that global trafficking has become a growing problem The two most common purposes for human trafficking are sexual exploitation and forced labor. Victims of sex trafficking are forced into one or more forms of sexual exploitation. It is important to note that sex trafficking and prostitution are not synonymous and that prostitution is simply one type of work performed by victims of sex trafficking. Sex trafficking is an umbrella term that may include commercial sex work such as prostitution, but also pornography, exotic dancing, stripping, live sex shows, mail-order brides, military prostitution, and sexual tourism. Although victims of sex trafficking can be of any age and of either sex, the majority are women and adolescent girls.

There are several recurrent tactics of manipulation used to coerce victims into situations of sex trafficking .Most commonly, victims are promised a good job, education, or citizenship in a foreign country or offered a false marriage proposal that is turned into bondage. Many

(c) The International Journal of Indian Psychology, ISSN 2348-5396 (e)| ISSN: 2349-3429 (p) | 100 


\section{Self-Efficacy and Positive Life Orientation in Prostitutes}

victims are sold into the sex trade by parents, husbands, and significant others, whereas others are unwillingly and forcibly kidnapped by traffickers. The most common tactic of coercion used among victims is debt bondage, an illegal practice where the victim has to pledge personal services in order to repay some form of debt, such as transportation into a foreign country or living expenses. 3 Sex traffickers may often approach families living in poverty and seek to purchase girls or young women with the promise of a better life in a richer nation.

\section{Male and transgender sex workers}

Male sex workers often enter sex work for different reasons to female sex workers. It is claimed that male sex work is often linked with the commercial gay scene in which drug use and alcohol is common among workers and clients. Additionally, a small proportion of male sex workers have female clients.

A study by Wilcox and Christmann (2006), which interviewed male sex workers in Yorkshire, found no forms of coercion among their sample population. However, while the majority of male sex workers are not subject to the same level of vulnerability and exploitation, young and particularly homeless men are susceptible to exploitative behaviour. In addition, few services and outreach programmes target male sex workers or are equipped to deal with their needs (UK NSWP, 2008c).

Information on the lives of transgender sex workers is also scarce. Many are said to suffer from the double stigmatisation of being a sex worker and transgender. It is claimed that in some cases, sex work is one of the only viable options for transgender people, turning to sex work to fund their treatments and experiencing difficulty in finding other forms of employment (UK NSWP, 2008c). Again, the services available to this group are very limited. Moreover, government policy has on the whole excluded male and transgender sex workers from policy discussions and tended to focus all of its attention on female sex work (Whowell, 2010).

\section{Direct and indirect sex work}

Direct sex work refers to services, such as indoor and outdoor prostitution as well as escort services. This type of sex work typically involves the exchange of sex for a fee in which genital contact is common.

Indirect sex work refers to services, such as lap dancing, stripping and virtual sex services (over the internet or phone). Genital contact is less common in this type of sex work; however, a fee is still exchanged for the services. People who are sex workers are people who also might self-identify as or be identified as Exotic dancers/strippers, Phone sex operator, Escorts, Prostitutes, Porn actors/actresses etc.

\section{Positive Life Orientation}

Positive thinking and positive orientation towards crises has wide implications in recovery from stressful events as well as in one's reactions to everyday experiences. The desired positive effect works through perceived positive appraisal of the given situation. The positivity bias creates a 


\section{Self-Efficacy and Positive Life Orientation in Prostitutes}

desired state of mind necessary to deal with life positively, in general. This tendency yields positive results aimed at life enhancement in all circumstances.

The authors studied the positivity bias and introduced the concept of positive life orientation (PLO). They developed a scale on PLO which was initially studied in relation to recovery from myocardial infarction (Agrawal, Dalal, Agarwal, \& Agarwal, 1995). PLO was defined as a positive mindset, in which reality is construed in a manner so as to derive a positive meaning out of any given situation. This positivity bias is a predisposition to selectively focus one's attention on the brighter side of one's life experiences. The operational definition of PLO describes it as the ability of the individual to emphasize the positive aspects of a crisis, to make positive comparisons, and maintain a positive attitude towards life in general.

\section{Self-Efficacy}

Self-efficacy theory was originated from Social Cognitive theory by Alberta Bendura. Selfefficacy is the belief that one has the power to produce that effect by completing a given task or activity related to that competency. Self-efficacy relates to a person's perception of their ability to reach a goal. It is the belief that one is capable of performing in a certain manner to attain certain goals. It is the expectation that one can master a situation, and produce a positive outcome. Self-efficacy is an important concept in positive psychology.

Bandura's Social Cognitive Model says that there are 3 factors that influence self-efficacy:

1. Behaviors

2. Environment, and

3. Personal/ cognitive factors.

They all effect each other, but the cognitive factors are important. Self-efficacy developing from mastery experiences in which goals are achieved through perseverance and overcoming obstacles and from observing others succeed through sustained effort. Self-efficacy and self-esteem are different concepts, but related. Self-efficacy relates to a person's perception of their ability to reach a goal, whereas self-esteem relates to a person's sense of self-worth. Self-efficacy is the most important precondition for behaviour change.

\section{Rationale of the Research}

In Indian society people has stereotype thinking about sex workers. People are not very open about this topic. India has been reserved by the fact that sexuality in any form is rarely discussed openly. Even sex workers are human beings so why can't they be treated with equality, so what if they are in such profession. The researcher wants to do the work on this topic particularly because, she have heard lot of stories about sex worker's personal life, which motivates her to do research work in this area. As we all understand that both mental and physical healths are very important in an individual's life. So why this discrimination? Sex workers should be given equal

(C) The International Journal of Indian Psychology, ISSN 2348-5396 (e)| ISSN: 2349-3429 (p) | 102 


\section{Self-Efficacy and Positive Life Orientation in Prostitutes}

rights. They should be provided with proper medication and treatment when required. But willingly no one takes a first move to do something for these sex workers just because they are termed as "sex workers". This is an issue about which people should get aware of and stop being a stereotype thinker. The researcher has attended some lectures on sex workers and their lives, which really motivated her to work on this topic. She has lot of queries to get an answer for regarding this topic. Many factors drive women to enter as sex worker like the first and the most obvious is money-. Prostitution or sexual gratification for money is perhaps the world's oldest known trade. The changing face of the dark trade has now broadened to include street prostitution, massage brothels, escort services, strip clubs, lap dancing, phone sex, child prostitution and sex tourism. This high risk industry is fraught with violence and abuse but keeps growing by the day. Then second factor is low education, dropping out school, financial need, homeless and runaway issues, violence, victims of trafficking, one of the push factor is children living in a sex work environment etc. reasons for getting into this field could be many more but these are some major factors which make girls or young women enter into sex work. The most important point which really motivated the researcher to work on this topic was the experience the researcher had while talking to her sister on prostitutes and their personal lives as her sister shared some experience she had when she met them through an NGO where she worked.

\section{REVIEW OF LITERATURE}

Review of literature suggests that many studies have been conducted in the area of prostitution. The present chapter deals with the review of existing sex worker research.

Melissa Farley who conducted an extensive research on prostitution in the US in 2015, observes in her "Prostitution: Fact sheet on Human Rights Violations", that prostitution involves sexual harassment, battering, rape, verbal abuse, childhood sexual abuse and a violation of human rights on the whole. Farley writes, "Whether it is being sold by one's family to a brothel, or whether it is being sexually abused in one's family, running away from home, and then being pimped by one's boyfriend, or whether one is in college and needs to pay for next semester's tuition and one works at a strip club behind glass where men never actually touch you - all these forms of prostitution hurt the women in it."

Qiao S, et al. (2014) conducted a study on Psychological Fears among Low-Paid Female Sex Workers in Southwest China and Their Implications for HIV Prevention. Compared with other women of reproductive age, female sex workers are taking a disproportionately high burden of HIV infection due to biological, behavioral and structural risk factors. These female sex workers are more prone, as their "clients" refuse to use protective devices or methods. Here the low-paid sex workers are more vulnerable to this because of their social demographic characteristics, life history and working environment. Some worried about breaching their sex worker identity (either to family members or acquaintances). Some feared being arrested by the police. Some expressed their fear of not getting paid by clients. The relationship between fear of HIV infection 


\section{Self-Efficacy and Positive Life Orientation in Prostitutes}

and condom use is consistent with psychological fears. Though fear of breaching their identity might be an important issue that needs to be addressed in HIV prevention. Psychological fears can play an important role in HIV prevention social marketing or other public health campaigns. Strengthening their trust in HIV-testing facilities and health care providers will be very important to promote access to testing and other HIV prevention and treatment services.

Dr. Subadra Panchanadeswaran, et al. (2010) conducted a study on " a descriptive profile of abused sex workers in India”. This descriptive study presents the profiles of abused female sex workers (FSWs) in Chennai, India. Of 100 abused FSWs surveyed using a structured questionnaire, severe forms of violence by intimate partners were reported by most (98\%) respondents. Of the total sample, $76 \%$ experienced violence by clients. Sexual coercion experiences of the FSWs included verbal threats (77\%) and physical force (87\%) by intimate partners and forced unwanted sexual acts (73\%) by clients. While $39 \%$ of the women consumed alcohol before meeting a client, $26 \%$ reported that their drunkenness was a trigger for violence by clients. The findings suggest that there is an urgent need to integrate services, along with public-health interventions among FSWs to protect them from violence. Recognition of multiple identities of women in the contexts of intimate relationships versus sex work is vital in helping women to stay safe from adverse effects on health.

Rössler W1, et al. (2010), Department of General and Social Psychiatry, Psychiatric University Hospital Zurich, Switzerland, conducted a study about "the mental health of female sex workers" which reveals as the a quota-sampling strategy was the best possible alternative. Sex workers were contacted at different locations in the city of Zurich. They were interviewed with a computerized version of the World Health Organization Composite International Diagnostic Interview. Additional information was assessed in a structured face-to-face interview. It was found that 193 interviewed female sex workers displayed high rates of mental disorders. These mental disorders were related to violence and the subjectively perceived burden of sex work.

Xiaoyi Fang, et al. (2007), Beijing Normal University Institute of Developmental Psychology, Beijing, China conducted a study on "Profile of female sex workers in a Chinese county: Does it differ by where they came from and where they work?” which reveals that most existing studies on commercial sex in China have been conducted in large cities or tourist attractions. Using data from 454 female sex workers in a rural Chinese county, The findings of the current study underscore the urgent needs for effective HIV/STD prevention intervention and mental health promotion program among female sex workers in China. The data in the current study suggest a strong association of individual profile with the economic conditions of work sites and residence status (in-province residency versus out-province residence) which suggests that such efforts must take the social and cultural contextual factors of their working environment (and sexual risks) into consideration. 


\section{Self-Efficacy and Positive Life Orientation in Prostitutes}

Lowman (2000), profiles the murders of sex workers in British Columbia from 1964 to 1998. Lowman argues the media accounts of the "get rid of prostitutes" activities that were initiated by politicians, police and residents during the 1980s contributed to a "'sharp increase in the murders of prostitutes after 1980. Lowman argues there are two forms of violence against prostitutes: situational (violence that occurs during the "course of a transaction") and predatory (premeditated violence). However, this violence must be understood as part of a "“continuum of violence against women more generally".

Schissel et al.(1999) explored the "culture of violence" experienced by young prostitutes by analyzing youth probation files in Regina and Saskatoon. In addition to uncovering high levels of childhood physical and sexual abuse among youth prostitutes, the authors find several examples of indirect and direct victimization. As the authors note: "“prostitution creates a context in which those youth who are involved will run a high risk of being damaged by a predator or by themselves - whether directly through assault and self-injury or indirectly through high-risk behaviour”"

Minichiello, et al. (1999) examined customers of male prostitutes by asking male sex workers their perceptions of the characteristics of clients. One hundred and eighty-six sex workers participated in the study, providing information on 2,088 encounters and profiles for 1,776 clients. Most clients were perceived as being "middle class." "Rich" clients tended to use services provided by an escort agency, while "poor" clients used the services of street workers. Most clients were identified as being gay (45\%) or bisexual (31.3\%). Drug and alcohol use by clients before the sexual encounter was uncommon. Customer violence was reported infrequently (occurring more frequently with street clients than with other types of clients.

Mansson et al. (1999) research included interviews with 23 women between the age of 20 and 58 who had left the sex trade in Sweden.[13] The authors suggest the decision to enter prostitution is influenced by a difficult childhood (e.g. physical, sexual and emotional abuse), accompanied by low self-esteem. " (e.g., difficulty understanding their life in prostitution, living in marginal situations, problems with intimate and close relationships). The authors suggest an individual's commitment to change plays an important role in the process of exiting, a process encouraged by a variety of interpsychological and interpersonal factors. "

Dorais (1996) suggested that some male victims of childhood sexual abuse might become involved in "aggressive prostitution" as a means of diverting revenge against the true aggressor.

Bartek, et al. (1993) conducted interviews with 20 juvenile delinquents involved in prostitution, 20 non-prostitute juvenile delinquents and 20 control subjects. Respondents were asked questions based on the Moral Judgment Interview (MJI) and Joffe and Naditch's coping and defending test. Delinquents characterized as "low coping" made "“lower level moral judgments on the prostitution dilemma than on the less personally relevant MJI dilemmas,"” revealing a 


\section{Self-Efficacy and Positive Life Orientation in Prostitutes}

relationship between moral reasoning and moral judgment.The psychology literature provides information on the short- and long-term impact of youth involvement in prostitution. However, most of these studies place the locus of responsibility for the decision to prostitute within the individual. In other words, it does not account for structural variables (e.g., poverty, unemployment, lack of housing) that also impact a youth's decision to enter the sex trade. Some researchers, however, have combined psychological and sociological variables to address this critique. Edney (1988 and 1990) argued that young prostitutes who had been sexually abused during childhood experienced a severe loss of self-esteem, and they exhibited poor physical and mental condition; however, their decision to prostitute was also affected by their social structure (i.e., cultural factors, gender stereotypes, family schools, employment structures, etc.). For young female prostitutes, Edney's (1990) research suggests that "“...sexual abuse and the victims' responses to sexual abuse prepared and trained the young girls for prostitution."

While focusing on the psychological development of young prostitutes and the psychological impact of being involved in the sex trade, Coleman (1989) found that disruptions in the psychosexual and psychological development of young males may contribute to their participation in "“'destructive and non-ego enhancing prostitution activities."

Many youth who run away from home (as noted above, often from physically and sexually abusive home environments) may be drawn to the streets by a sense of excitement and a desire for money and independence (Michaud, 1988). However, once on the streets, the research indicates that some of these youth may turn to prostitution as a means of subsistence. He noted that problems associated with homelessness (such as youth unemployment) provide the impetus for some youth to enter prostitution as a source of income.

There is very little research on if, why, and how prostitutes choose to leave the sex trade. Boyer (1986) examined youth in the care of the Seattle Youth and Community Services (SYCS) to "'identify factors and attributes precipitating a youth's decision to seed or sever links with services and continue or discontinue prostitution and 'street' behavior." "The youth who successfully exited 'street' lifestyles compared to those who have not exited had experienced less child abuse prior to street involvement, had spent more time with parents or parental figures, and had become involved in street life at a later age.”"

\section{METHODOLOGY}

\section{Objective}

To measure Positive Life Orientation and Self-Efficacy in prostitutes and general population female

Assumption- Self-Efficacy and Positive Life Orientation will be higher in prostitutes than general population female.

(C) The International Journal of Indian Psychology, ISSN 2348-5396 (e)| ISSN: 2349-3429 (p) | 106 


\section{Self-Efficacy and Positive Life Orientation in Prostitutes}

\section{Sample}

The sample of the present study comprised of 50 general population female and 50 prostitutes.

\section{Method of Sampling}

Incidental sampling was used for data collection in the present study to collect the data.

\section{Research Design}

The present study research design is Ex-post facto research design

\section{Tools Used}

1. Self-Efficacy Scale: The scale intends to assess the level of self-efficacy. It consists of 22 items, dealing with eight factors which are (Self regulatory skills, Self influence, Self confidence, Social achievement, Self, Self-evaluation, Self -esteem and Self-cognition) in this scale the items arein two forms i.e, positive and negative. In this scale each item describes human self-efficacy in different situations in the society. The scale presents belief items to denote self-efficacy on the scale. It was developed by (Hindi Version) Dr. (Mrs.) G.P.Mathur and Dr. (Mrs.) Raj Kumari Bhatnagar.

Reliability: reliability co-efficient of the scale was measured by test-retest on a sample of 600 (300 male and 300 female). In male it ranges between .73 to .81 and in female .78 to .86 and is significant at 0.01 level of significance.

Validity: to obtain concurrent validity co-efficient of self -efficacy scale, the scale was compared with the views of experts' rating. Validity ranges in male .73 to 81 and in female .76 to .83 .

2. Positive Life Orientation Scale: The scale consists of 11 items about the tendency among people to interpret life situations in a positive or negative manner. It was developed By Dr. Manju Agrawal and Dr. Ajit K. Dalal in 1995.

RELIABILITY: The internal consistency of PLO scale is 0.86 , the split-half reliability is found to be 0.62 and the test-retest reliability coefficient obtained was 0.79 . Thus, all three reliability scores are high and suggest that the PLO scale is a highly reliable scale.

\section{Method of Data Collection}

The data collection of general population female was done in Amity University. Where the girls were told by the researcher about the present study and were instructed to cooperate and give the answers to the questions asked. Second population was prostitutes; the data collection was done in Delhi. The researcher went with an official letter to collect data from prostitutes. The researcher also had contacts which made it easier to go to the brothels and get data. Building a rapport with the prostitutes was not at all easy, it took 2 days to make them understand why the researcher wants to talk to them and need them to answer some questions. The researcher told them that she is doing a study on them to know them better on personal level. The questionnaires were given in Hindi as well, to understand it easily by listening the questions through the 


\section{Self-Efficacy and Positive Life Orientation in Prostitutes}

researcher as the prostitutes were illiterate. There are two different scales, There are 22 questions given here which the researcher request you to answer them by a tick on one of the five alternatives options which you think is appropriate according to you. Like this you have to attempt all the 22 questions. There are no right or wrong answers. There is no time limit, where ever you don't understand the question you are free to ask the researcher. All the information given by you will be kept confidential. After finishing these 22 questions go to the second scale which scale consists of 11 items which has four options that are ( not at all, somewhat, much and very much) the researcher requests you to answer each question by a tick on one of the options you think is appropriate according to you. There are no right or wrong answers. There is no time limit, where ever you don't understand the question you are free to ask the researcher. All the information given by you will be kept confidential.

\section{Statistical Analysis}

In the study the researcher has used the t-test to find out Self-Efficacy and Positive Life Orientation higher in prostitutes than in general population female.

\section{RESULT}

\section{Table 4.1 Showing Mean, SD and t-test}

\begin{tabular}{|l|l|r|r|r|r|}
\hline \multicolumn{2}{|c|}{ Population } & Mean & \multicolumn{1}{c|}{ Std. Deviation } & \multicolumn{1}{c|}{ df } & \multicolumn{1}{c|}{ t } \\
\hline \multirow{2}{*}{ SES } & General population Female & -.4746 & .78375 & 98 & -3.353 \\
\cline { 2 - 6 } & Prostitutes & -.0748 & .31068 & 64.028 & -3.353 \\
\hline \multirow{2}{*}{ PLO } & General population female & 28.4600 & 4.38555 & 98 & -223 \\
\cline { 2 - 6 } & Prostitutes & 28.6200 & 2.57056 & 79.115 & -223 \\
\hline
\end{tabular}

The table 4.1 shows t-test results of Self -Efficacy and Positive Life Orientation in general population female and prostitutes.

The researcher assumed Self-Efficacy and Positive Life Orientation higher in prostitutes than general population female.

The present study result shows that Self-Efficacy is higher in general population female than prostitutes and no such difference in Positive Life Orientation in both the population.

One study reported by Zaplin ( 1998 ) suggested role of self-efficacy in life of prostitute. In the book name Female Offenders: Critical perspective and effective interventions by Ruth .T. Zaplin. There was a section (programs that work: working with prostitutes) in which there was a program organized named "Regaining Esteem Stopping Prostitution by Education and Continued Treatment (RESPECT). Evaluation of effective program shows several elements that promote successful outcomes. The most important is the inclusion of activities that enhance self-efficacy. Self-efficacy is defined as the confidence an individual has in specific areas. Often prostitutes have high self-efficacy in areas pertaining to their ability to provide prostitution services,

(c) The International Journal of Indian Psychology, ISSN 2348-5396 (e)| ISSN: 2349-3429 (p) | 108 


\section{Self-Efficacy and Positive Life Orientation in Prostitutes}

however do not have high self -efficacy in areas that can help to stop the offending behavior. This research mentions high self -efficacy among prostitutes but the same was not found in the present research.

The assumption that prostitutes will be higher on Self- Efficacy and Positive Life Orientation was the result of detailed discussion which researcher indulged in as a pilot study. When discussions were done it was found out that prostitutes did feel a sense of accomplishment and confident in themselves. They mention that their profession gave them the ability to give a respectful life to their children and they can give a better future to them. They said they perceive their profession as their ability to reach the goal of giving a better life to their children. This made the researcher wonder if the studies conducted so far on prostitution which revolve around negative constraints have been only one part of the picture. With this assumption the present research was planned. But the results concluded do not support this assumption. One of the reasons could be the tools themselves. Social desirability might have played a role in the present situation. Since the topic chosen is very specific, the tools also needed to be specific and suitable to the sample. This was not possible in the present research due to paucity of time. The researcher strongly feels that specific tools need to be developed with in-depth interviews to provide qualitative data for future research in this direction. This maybe initial step in the direction of study of psychology of prostitutes. There have also been demands of declaring prostitution as a profession. In itself, prostitution serves many purposes as it prevents- rape and marital abuse- both physical and sexual. Such studies may bring prostitution in another light and helps in understand their lives and psyche better.

\section{CONCLUSION}

The researcher assumed Self-Efficacy and Positive Life Orientation higher in prostitutes than general population female but the results concluded do not support this assumption. The present study result shows that Self-Efficacy is higher in general population female than prostitutes and no such difference in Positive Life Orientation in both the population.

\section{Suggestions}

1. More variables can be included like resilience, life satisfaction

2. Tools should be available in local languages.

3. More specific tools suitable to sample population are required.

\section{Limitations}

1. Limited sample size

2. Limited geographical area

\section{Acknowledgments}

The author appreciates all those who participated in the study and helped to facilitate the research process. 


\section{Self-Efficacy and Positive Life Orientation in Prostitutes}

Conflict of Interests: The author declared no conflict of interests.

\section{REFERENCES}

Allen, J., Balfour, R., Bell, R., \& Marmot, M. (2014). Social determinants of mental health. International Review Of Psychiatry

Baral, S., Beyrer, C., Muessig, K., Poteat, T., Wirtz, A., \& Decker, M. et al. (2012). Burden of HIV among female sex workers in low-income and middle-income countries: a systematic review and meta-analysis. The Lancet Infectious Diseases

Fajans, P., Ford, K., \& Wirawan, D. (1995). AIDS knowledge and risk behaviors among domestic clients of female sex workers in Bali, Indonesia. Social Science \& Medicine

Prostitution Research \& Education. Prostitutionresearch.com., from http://www.prostitutionresearch.com

Review of Related Literature - Research Papers - 3643 Words. StudyMode. from http://www.studymode.com/essays/Review-Of-Related-Literature-1494412.html

Rössler, W., Koch, U., Lauber, C., Hass, A., Altwegg, M., Ajdacic-Gross, V., \& Landolt, K. (2010). The mental health of female sex workers. Acta Psychiatrica Scandinavica,

Sexual behavior and condom use among patients with sexually transmitted diseases in Jinan, China. (2001). Am J Public Health

Stolzberg, S. (2005). Prostitution, Trafficking, and Traumatic Stress. Permj,

Wang, J., Jiang, B., Siegal, H., Falck, R., \& Carlson, R. (2001). Level of AIDS and HIV Knowledge and Sexual Practices Among Sexually Transmitted Disease Patients in China. Sex Transm Dis

Wilcox and Christmann (2006) from the website http://webarchive.nationalarchives.gov.uk/.../horr27c.pdf

Wright, N., \& Stickley, T. (2012). Concepts of social inclusion, exclusion and mental health: a review of the international literature. Journal Of Psychiatric And Mental Health Nursing

Yang, H., Li, X., Stanton, B., Chen, X., Liu, H., \& Fang, X. et al. (2005). HIV-Related Risk Factors Associated with Commercial Sex Among Female Migrants in China. Health Care For Women International

Yang, H., Li, X., Stanton, B., Fang, X., Lin, D., \& Mao, R. et al. (2005). Workplace and HIVrelated sexual behaviours and perceptions among female migrant workers. AIDS Care.

Zaplin, R. (1998). Female offenders. Gaithersburg, Md.: Aspen Publishers.

How to cite this article: Kewalramani S, Srivastava S (2017), Self-Efficacy and Positive Life Orientation in Prostitutes, International Journal of Indian Psychology, Volume 4, Issue 2, No. 96, ISSN:2348-5396 (e), ISSN:2349-3429 (p), DIP:18.01.191/20170402, ISBN:978-1-36584232-0 